\title{
Correction to: Developing a theory-based behavior change intervention to improve the prescription of surgical prophylaxis
}

\author{
Anna Leena Lohiniva ${ }^{1}$ (D - Iman Heweidy ${ }^{2} \cdot$ Samia A. Girgis ${ }^{2} \cdot$ Omar Abouelata $^{3} \cdot$ Caroline Ackley $^{4,5} \cdot$ Shady Samir $^{2}$. \\ Maha Talaat ${ }^{1}$
}

Published online: 17 February 2022

(c) Springer Nature Switzerland AG 2022

\section{Correction to: International Journal of Clinical Pharmacy https://doi.org/10.1007/s11096-021-01338-8}

Unfortunately, the headings were not included in the initial version of this article's Abstract section, and the "Ethics Approval" was also not included. In this correction, the same was corrected.

The original article has been corrected.

Publisher's Note Springer Nature remains neutral with regard to jurisdictional claims in published maps and institutional affiliations.

The original article can be found online at https://doi.org/10.1007/ s11096-021-01338-8.

Anna Leena Lohiniva

Lohinivaa@gmail.com

1 WHO Eastern Mediterranean Regional Office, Cairo, Egypt

2 Ain Shams University Hospitals, Cairo, Egypt

3 WHO Egypt Country Office, Cairo, Egypt

4 London School of Tropical Medicine and Hygiene, London, England, UK

5 Brighton and Sussex Medical School, Brighton, England, UK 